\title{
A novel Levator Ani Midurethral Support Via Single Vaginal Incision to Treat Stress Urinary Incontinence: Case Report
}

Lai-Yet Lam ( $\sim$ laiyetlammd@aol.com )

NewYork-Presbyterian Queens https://orcid.org/0000-0002-7768-1276

Janice Santos-Cortes

Mount Sinai Medical Center, Miami, Florida

Timothy O'Rourke

Brown University Warren Alpert Medical School

\section{Research Article}

Keywords: mesh midurethral sling, pelvic organ prolapse, stress urinary incontinence, urinary incontinence

Posted Date: July 22nd, 2021

DOI: https://doi.org/10.21203/rs.3.rs-559662/v1

License: (c) (i) This work is licensed under a Creative Commons Attribution 4.0 International License. Read Full License 


\section{Abstract}

\section{Introduction}

A novel native tissue midurethral support procedure, Levator Ani Midurethral Support via single vaginal incision, to treat patients with stress urinary incontinence is introduced in this case report. After mesh controversy, there is a need for a minimal invasive native tissue surgical procedure to treat stress urinary incontinence with minimal complication.

\section{Case Presentation}

A 51-year-old female with stress urinary incontinence had three mesh midurethral slings and one autologous fascia sling with severe infection that failed. She developed recurrent stress urinary incontinence and coital incontinence. After she was referred to our care, she was initially treated with urethral bulking injections which also failed. There were few alternatives left after failure of three mesh midurethral slings, one autologous fascia sling with severe infection and urethral bulking injections. The patient was successful treated with our novel native tissue midurethral support procedure, Levator Ani Midurethral Support via single vaginal incision. She remains continent 23 months after the Levator Ani Midurethral Support via single vaginal incision and her coital incontinence has also resolved. She reported she has no pelvic pain or dyspareunia.

\section{Conclusions}

After further study, this novel native tissue midurethral support procedure, Levator Ani Midurethral Support via single vaginal incision may meet the need for a minimal invasive native tissue surgical procedure for the treatment of stress urinary incontinence with minimal complication.

\section{Introduction}

Stress urinary incontinence (SUI) is reported to affect between $4 \%$ and $35 \%$ of adult women [1]. After the US Food and Drug Administration approval in 1996 of mesh midurethral sling (MUS) to treat SUI, MUS has been widely used and extensively studied [2-5]. Nearly all the surgical treatments for SUI developed since 1996 involved the use of mesh for support of midurethra, such as transvaginal tape (also known as retropubic mesh sling), trans-obturator tape and single incision sling [6-8], all of which are varieties of MUS. After mesh controversies, the surgical treatments developed before MUS, including autologous fascia sling (fascia sling on a string), Burch colposuspension and urethral bulking injections, have had a resurgence for treatment of SUI [9-16].

In 2012, Wei, et al. reported the reduction of one-year post-operative de-novo urinary incontinence (UI) rate from $43 \%$ to $27.5 \%$ for MUS surgery concomitant with pelvic organ prolapse (POP) surgery for patients without pre-operative SUI [17]. The lead author (LYL) developed a novel native tissue procedure to reduce de-novo post-operative UI by performing Levator Ani Midurethral Support via single vaginal incision 
(LAMS) as part of anterior repair during POP surgery for patients without pre-operative SUI. A photograph of LAMS procedure before anterior vaginal epithelium closure in a patient with Stage 4 POP, without preoperative SUI, previous surgery or scar tissue, is shown in Figure 1. (Written consent was obtained from the patient of the photograph for the use in this case report.) Subsequently, LAMS was offered as an option for patients who have MUS failure or have declined MUS. In this case, the patient was referred for evaluation of persistent SUI following failure of three MUS and one autologous fascia sling. We were able to successfully treated this patient's persistent SUI with LAMS. The timeline of events is shown in Figure 2. This case report details LAMS procedure. (Written consent to report this case was obtained from the patient of the case.)

\section{Case Presentation}

A 51-year-old female, G5P2032, who had two spontaneous vaginal deliveries and two ectopic pregnancies, with medical history notable for chronic tobacco use, gastroesophageal reflux, hypercholesterolemia, hypothyroidism, anxiety, depression, and allergic rhinitis, was referred for evaluation of persistent stress urinary incontinence (SUI) after multiple prior surgeries by outside urogynecologists.

At age 40, the patient underwent total vaginal hysterectomy, McCall culdoplasty, anterior repair, and retropubic mesh sling placement for menorrhagia and SUI. One year later, partial mesh exposure was identified, requiring excision. She developed recurrent SUI, confirmed with urodynamics and physical examination. At age 42, she underwent placement of another retropubic mesh sling. At age 45, she had recurrent mesh exposure requiring laparoscopic and vaginal excision of mesh. She underwent urodynamic testing four months later, which demonstrated SUI without intrinsic sphincter deficiency and no detrusor overactivity. Five months after excision of mesh, she underwent a laparoscopic paravaginal cystocele repair and a third retropubic mesh sling placement. Post-operatively she developed urinary retention, requiring clean intermittent catheterization. Three weeks later, $1.5 \mathrm{~cm}$ of sub-urethral mesh was excised for urinary obstruction and incision separation. Her SUI returned immediately following sling excision, and she returned to the operating room for further mesh excision and retropubic autologous rectus fascia sling placement. This was complicated by post-operative abdominal wound hematoma, requiring wound exploration and wound VAC for closure.

At age 51, she was referred to our care for mixed urinary incontinence with component of both stress and urge. She also had coital urinary incontinence. She wore incontinence pads during her daily activities. She continued to smoke cigarettes. Physical examination revealed vaginal scarring. She had no urinary retention, and no SUI was elicited while supine or standing. She was started on mirabegron without improvement and underwent urodynamics, notable for low capacity $(218 \mathrm{~mL})$, normal compliance, no evidence of detrusor overactivity, and a max flow rate of $4.0 \mathrm{~mL} / \mathrm{sec}$ at Pdet qmax $26 \mathrm{~cm}$ $\mathrm{H}_{2} \mathrm{O}$ with a non-sustained detrusor contraction characterized as mild detrusor underactivity. Her post-void residual volume was low $(10 \mathrm{ml})$. Urodynamics did not demonstrate $\mathrm{SUl}$, but it was detected upon catheter removal with a full bladder. The decision was made to proceed with urethral bulking injections. 
This was successful with injections at 3,6, and 9 o'clock positions with excellent coaptation of the urethra. One month later she had persistent stress and urge urinary incontinence. She was counseled on the limited options that were available after failure of three MUS, one autologous fascia sling with severe infection and one set of urethral bulking injections. She opted to proceed with LAMS.

In preparation for surgery, she was placed on vaginal estrogen cream to facilitate dissection of the tissue layers. She was counseled to stop smoking in order to avoid infection and enhance healing after surgery. After one month, she was taken to the operating room. Under general anesthesia, she was placed in lithotomy position, prepped and draped in the usual manner. 1\% Lidocaine with 1/100,000 epinephrine was injected on the midline of the anterior vaginal epithelium from $0.5 \mathrm{~cm}$ to approximately $4 \mathrm{~cm}$ below the urethral meatus. An incision was then made on the hydro-dissected vaginal epithelium. The vaginal epithelium was then separated from the underlying vesicovaginal fascia sharply and bluntly. The vaginal epithelium was dissected as lateral as possible until it was at least 2-3 cm above the retro-pubic space, allowing space to place serial plication sutures at the level of mid-urethra. A few residual synthetic mesh fibers from previous surgeries were identified and excised. A 0-Vicryl suture on a UR- 6 needle was placed in a down to up manner, posterior to anterior, on the vesicovaginal fascia as lateral and as deep as possible on the patient's left side to include the puborectalis muscle. The same suture was brought to the right side, and placed in a up to down manner, anterior to posterior, again as lateral and as deep as possible to include the contralateral puborectalis muscle (Figure 3). The suture ends of the resulting inverted $U$ shape were then tied together to bring the puborectalis muscle from the two sides to the midline to support the mid-urethra. After the suture was tied, a more lateral portion of the muscle is then accessible. A second suture was then used to make another inverted $U$ plication. This was repeated a third time to include the puborectalis muscle to assure good support of the midurethra. Plication was technically challenging due to the significant scar tissue. The optimal result of complete mobilization of the puborectalis muscles with apposition in the midline (Figures 4-5) was not possible; there was a small suture bridge between the two sides of puborectalis muscle (Figures 6-7). The patient was observed overnight and failed trial of void on post-operative Day 1 . She subsequently passed an outpatient voiding trial on post-operative Day 3 . She developed recurrent urinary retention requiring temporary clean intermittent catheterization for one month.

At the time of this report, twenty-three months post-operatively, she remains dry except for rare urgency incontinence which is managed with timed voiding every two to three hours. She is very pleased with the outcome of LAMS procedure because she no longer has to use incontinence pads and no longer has coital urinary incontinence. She reported improved sexual satisfaction and no de-novo pelvic pain.

\section{Conclusions}

The standard surgical treatment for SUI involves the use of mesh midurethral sling (MUS) [2-5]. Although the US has not suspended the use of MUS after mesh controversies, many patients with SUI and/or POP are aware of mesh controversies and choose not to use mesh [9-11]. For patients with SUI and/or POP, non-mesh options such as autologous fascia sling (fascia sling on a string), Burch colposuspension and 
urethral bulking injections are often being used [12-16]. Autologous fascia sling involves harvesting of either rectus fascia or fascia lata and is a more extensive procedure [12-13]. Burch colposuspension requires either a mini abdominal incision or laparoscopy [14-15]. The efficacy of urethral bulking injections for treating SUI is not known [16]. A native tissue minimal invasive procedure with minimal complications to treat SUI is needed.

After failure of three MUS, autologous fascia sling was used for this patient. However, she developed severe abdominal wound infection from the autologous fascia sling and had recurrent SUI. Urethral bulking injections was attempted, but it did not resolve her SUI. Because her history of the severe abdominal wound infection, she chose not to have any procedure that involved abdominal incisions including laparoscopic Burch colposuspension. Even though she was told the success rate of LAMS was uncertain due to many previous surgeries and possible dense scarring, the patient opted for LAMS which involves only one single $3-4 \mathrm{~cm}$ vaginal incision.

LAMS is a single vaginal incision native tissue procedure for the treatment of SUI. Anatomically, there are no major vessels or nerves in the vicinity of the single vaginal incision or the lateral dissection of the avascular plane underneath the vaginal epithelium during the LAMS procedure. The whole procedure is done under direct visualization. For all the cases of LAMS, mainly concomitant with POP surgeries, the only peri-operative complications were urinary infection and urinary retention; there were no other complications such as bleeding, visceral or nerve injuries. Patients reported no de-novo urgency incontinence, de-novo pelvic pain or dyspareunia. LAMS is a native tissue procedure which use only absorbable sutures; therefore, there is no source for tissue reaction which might lead to pelvic pain and dyspareunia in some patients. LAMS itself will not improve patient's sexual satisfaction; in this case, the patient's sexual satisfaction improved because LAMS resolved her coital incontinence. Since the suturing is done as lateral as possible away from the mid-urethra in order to include the puborectalis muscle, the possibility of trauma to the mid-urethra should be minimal.

A challenge with LAMS procedure might be the wrist motion that is required to put the suture as lateral and as deep as possible to include the levator ani muscle in the tight space underneath the pubic bone.

This is the first report of a novel single vaginal incision native tissue procedure, Levator Ani Midurethral Support via single vaginal incision (LAMS), to treat women with stress urinary incontinence (SUI) after failure of three mesh midurethral slings (MUS), one autologous fascia sling with severe infection and one set of urethral bulking injections. Even though there was a small suture bridge due to the severe scarring in this case, the patient's SUI was successfully treated. After further study, LAMS may potentially meet the need for a minimal invasive native tissue surgical procedure for the treatment of SUI with minimal complication.

\section{Declarations}

Acknowledgements: None 


\section{i. Funding: None}

ii. Conflicts of interest/Competing interests: LY. Lam, J. Santos-Cortes, and T. O'Rourke declare that they have no conflict of interest.

iii. Ethics approval: Not applicable

iv. Consent to participate: Not applicable

v. Consent for publication: Written consent was obtained from the patient of the photograph for the use in this case report. Written consent to report this case was obtained from the patient of the case.

\section{vi. Availability of data and material: Not applicable}

vii. Code availability: Not applicable

viii. Authors' contributions: JS and TO performed the surgery of the case with LYL assisting. The manuscript was conceived by JS and LYL. TO and LYL acquired the data. LYL performed the literature review and drafted the introduction and discussion portion of the case report. TO, LYL and JS drafted the case portion of the case report. All authors critically reviewed the manuscript for important intellectual content and approved it in its final version. All authors agree to be accountable for all aspects of the work in ensuring that questions related to the accuracy or integrity of any part of the work are appropriately investigated and resolved.

\section{References}

1. Luber, KM. The Definition, Prevalence, and Risk Factors for Stress Urinary Incontinence. Rev Urol. 2004; 6(Supple 3): S3-S9.

2. American Urogynecologic Society (AUGS), Society for Urodynamics, Female Pelvic Medicine and urogenital reconstruction (SUFU). Position Statement. Mesh Midurethral Slings for Stress Urinary Incontinence. Updated February 2018. https://www.augs.org/assets/1/6/AUGS-

SUFU_MUS_Position_Statement.pdf Retrieved February 1, 2021

3. Cody J, Wyness I, Wallace S, Glazener C, Kilonzo M, Stearns S, et al. Systematic review of the clinical effectiveness and cost-effectiveness of tension-free vaginal tape for treatment of urinary stress incontinence. Health Technol Assess 2003:7:iii,1-189

4. Novara G, Artibani W, Barber MD, Chapple CR, Costantini E, Ficarra V, et al. Upated systemiatic review and meta-anaylsis of the comparative data on colposuspension, pubovaginal slings and midurethral tapes in the surgical treatment of female stress urinary incontinence. Eur Urolo 2010:58:218-38

5. Rehman H, Bezerra CC, Bruschinis H, Cody JD, Traditional suburetrhal sling operations for urinary incontinence in women. Cochrane Database Sys rev 2011:CD001754

6. Ulmsten $U$, Henriksson $L$, Johnson $P$ varhos $G$, An ambulatory surgical procedure under local anesthesia for treatment of female urinary incontinence. Int Urogynecol J Pelvic Floor Dysfunct 
1996;7:8-5; discusssion 5-6

7. Delorme E. Transobturator urethral suspension: mini-invasive procedure in the treatment of stress urinary incontinence in women, Prog Urolo 2001;11:1306-13.

8. Nambiar A, Cody JD, Jeffery St, Aluko P. Single-incision sling operation for urinary incontinence in women. CochraneDatabase Syst Rev 2017;7:CD008709

9. Chien P. The mess of mesh. British J Obstet Gynaecol, 2020 Jan;127(1):1-2. doi: 10.1111/14710528.16008

10. Chang J, Lee D, Midurethral slings in the mesh litigation era. Transl Androl Urol 2017;6:S68-S75.

11. Souders CP, Lilber KS, McClelland L, Wood LN, Souders AR, Steiner V, et al. The Truth Behind Transvaginal Mesh Ltigation: Devices, Timelines, and Provider Charateristics. Female Pelvic Med Resonstru Surg 2018;24:21-5

12. Aldrige AH. Transplantation of fascia for relief of urinary stress incontinence. Am J Obstet gynecol 1942;44:398-411.

13. Osman NI, Hillary CJ, Mangera A, Aldamanhoori R, Inman RD, Chapple CR. The Midurethral Fascial "Sling on a String": An Alternative to Midurethral Synthetic Tapes in the Era of Mesh Complications. European Urology. 2018;74:191-196. doi:10.1016/j.eururo.2018.04.031

14. Burch JC. Urethrovaginal fixation to Cooper's ligament for corrction of stress incontinence, cystocele, and prolapse. Am J Obstet Gynecol 1961;81:281-90

15. Langebrekke A, Dahlstrøm B, Eraker R, Urnes A. The laparoscopic Burch procedure. A preliminary report. Acta Obstet Gynecol Scand 1995 Feb;74(2):153-5.

16. Mamut A, Carlson KV. Periurethral bulking agents for female stress urinary incontinence in Canada. Can Urol Assoc J. 2017 Jun;11(6Suppl2):S152-S154. doi: 10.5489/cuaj.4612. PMID: 28616117; PMCID: PMC5461150.

17. Wei JT, Nygaard I, Richter HE, Nager CW, Barber MD, Kenton K, et al. A midurethral sling to reduce incontinence after vaginal prolpase repair. N Engl J Med 2012;366:2358-67

\section{Figures}




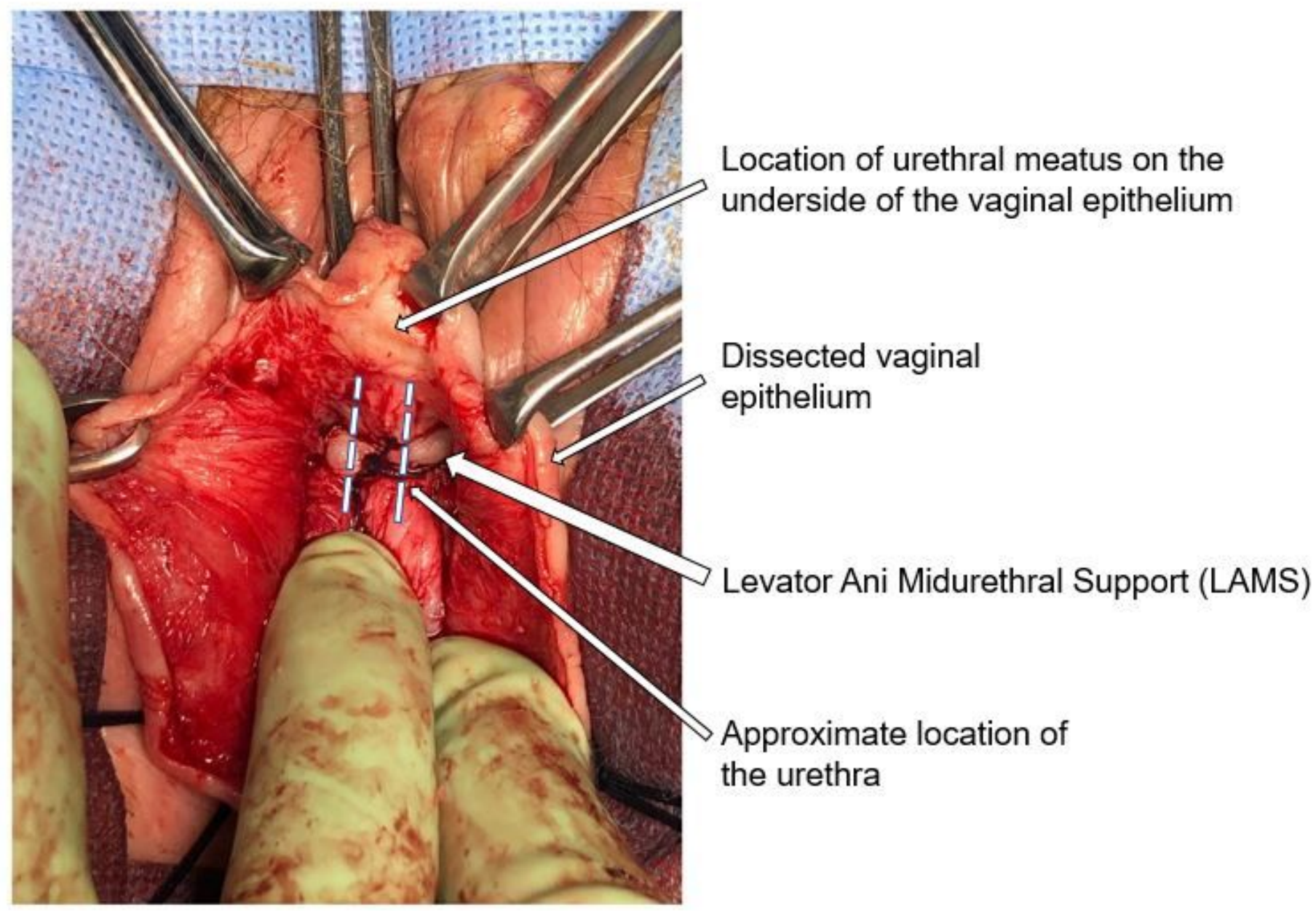

\section{Figure 1}

Photograph of LAMS after three passes of plication of levator ani muscle, before trimming of excess vaginal epithelium and anterior repair, showing support of the midurethra by a strong band of muscle. This is for a patient without scar tissue and there is no suture bridge. (Written consent was obtained from the patient of this photograph.) 


\section{Outside Urogynecologists}

\# 1 Retropubic mesh sling for SUI

Mesh exposure and excision, recurrent SUI

\#2 Retropubic mesh sling

\section{Our Care}

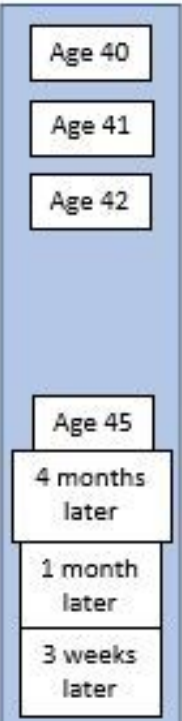

Urinary obstruction, mesh excision, recurrent SUI. Autologous rectus fascia sling; severe wound infection.
Recurrent SUI

\#3 Retropubic mesh sling
Recurrent mesh exposure, mesh excision

\begin{tabular}{|l|}
$\qquad$ Recurrent SUI \\
$\qquad 3$ Retropubic mesh sling \\
\hline $\begin{array}{l}\text { Urinary obstruction, mesh excision, recurrent SUI. } \\
\text { Autologous rectus fascia sling; severe wound infection. }\end{array}$ \\
\hline
\end{tabular}

Stress and urge urinary incontinence. Coital urinary incontinence. Urethral bulking injections.

Persistent stress and urge urinary incontinence. Coital urinary incontinence. Levator Ani Midurethral Support via single vaginal incision (LAMS).

23 months post-LAMS

Remains dry except for rare urgency incontinence which is managed with timed voiding every two to three hours. No longer has to use incontinence pads and no longer has coital urinary incontinence. She reported improved sexual satisfaction and no de-novo pelvic pain.

\section{Figure 2}

Timeline of all the treatments the patient received from outside urogynecologists (on the left) and under our care (on the right). The final outcome of the LAMS treatment is summarized at the bottom. Surgical treatments are highlighted in boldface type 


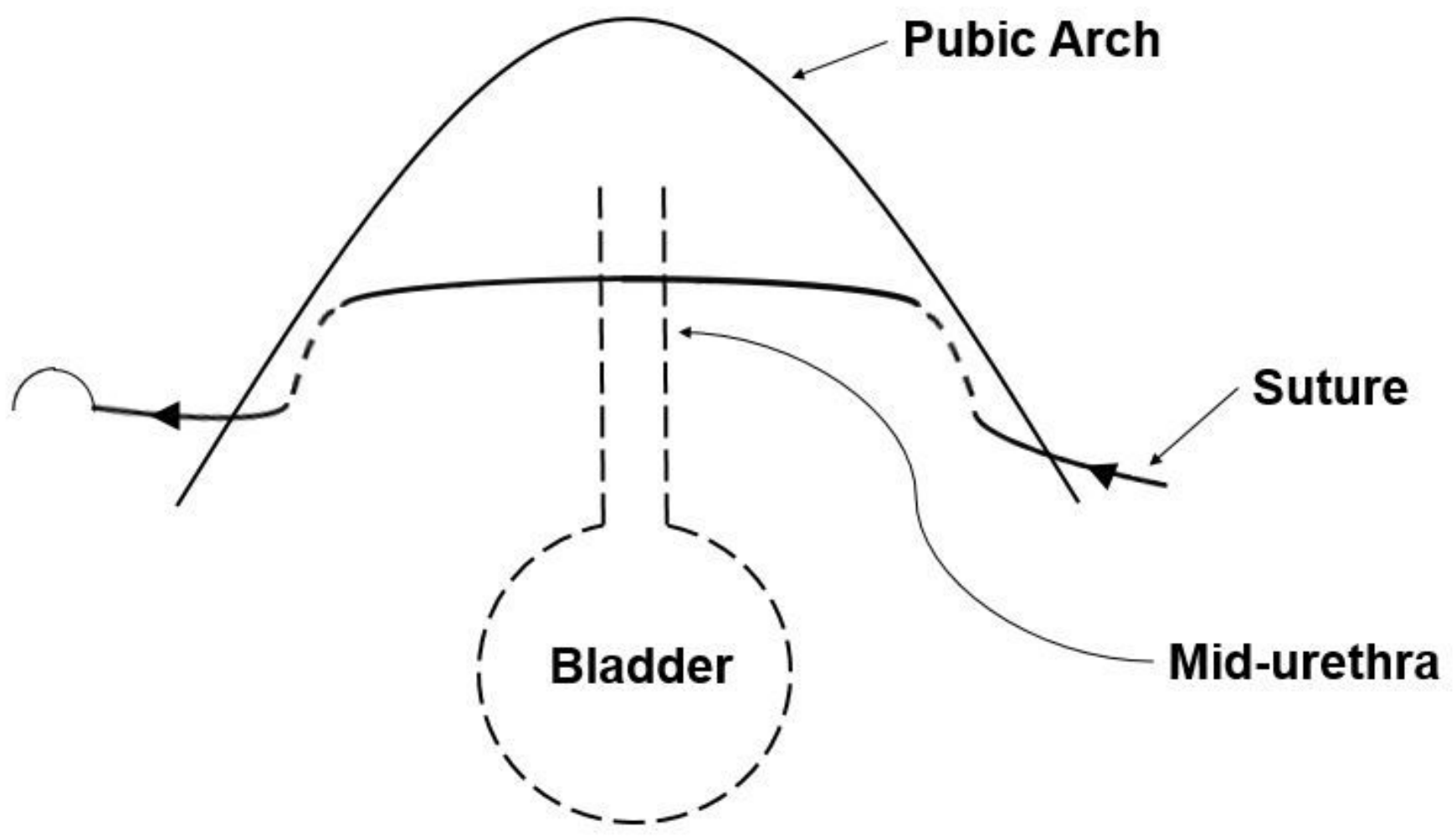

Figure 3

Schematic drawing of LAMS showing first pass of plication, before the suture ends are tied. The procedure is described in detail in the case

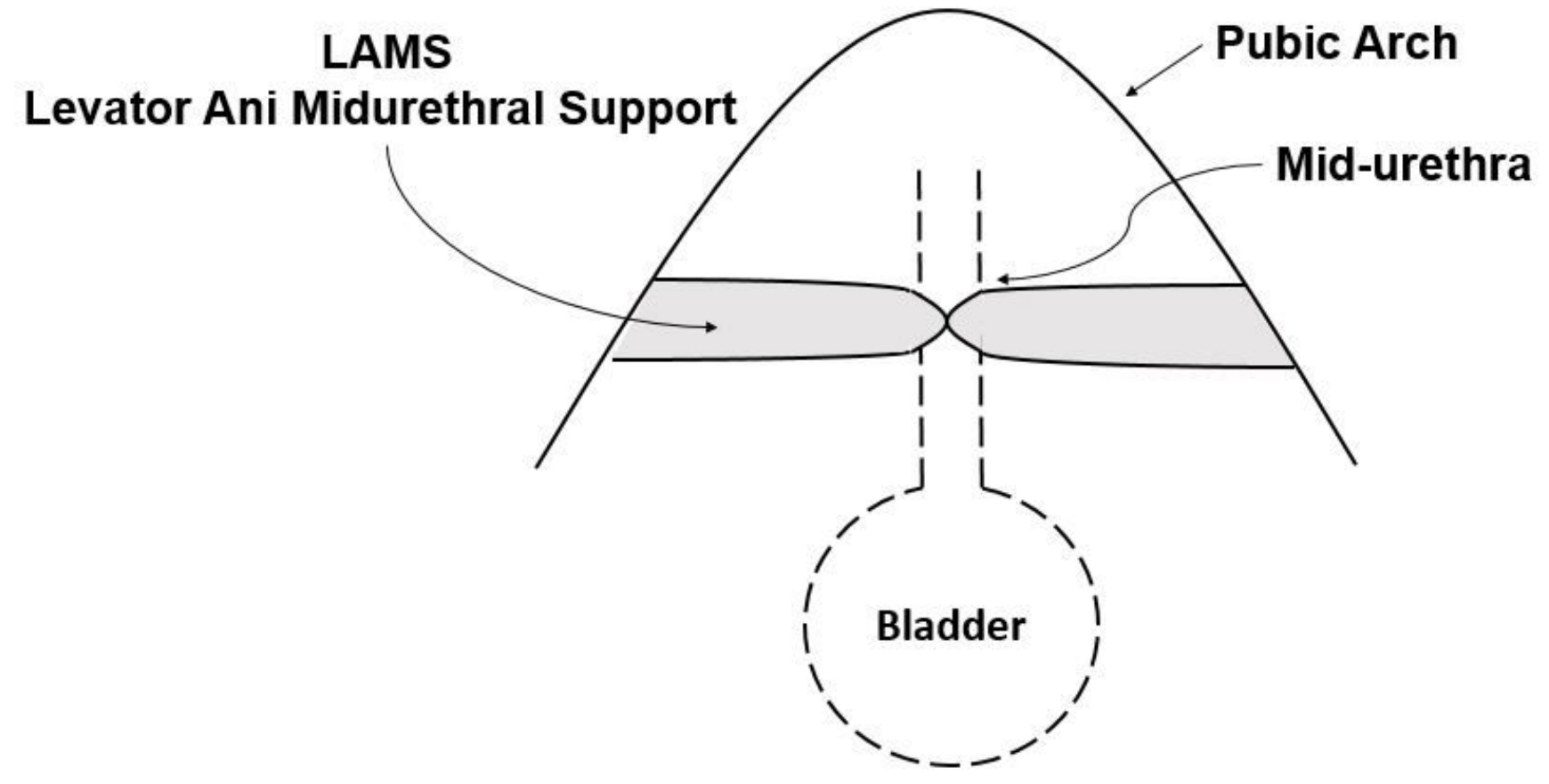


Figure 4

Schematic drawing of LAMS after three passes of plication of levator ani muscle, showing support of the midurethra by a strong band of muscle; for a patient without scar tissue or suture bridge. This schematic drawing corresponds to the photograph of Figure 1

\section{LAMS}

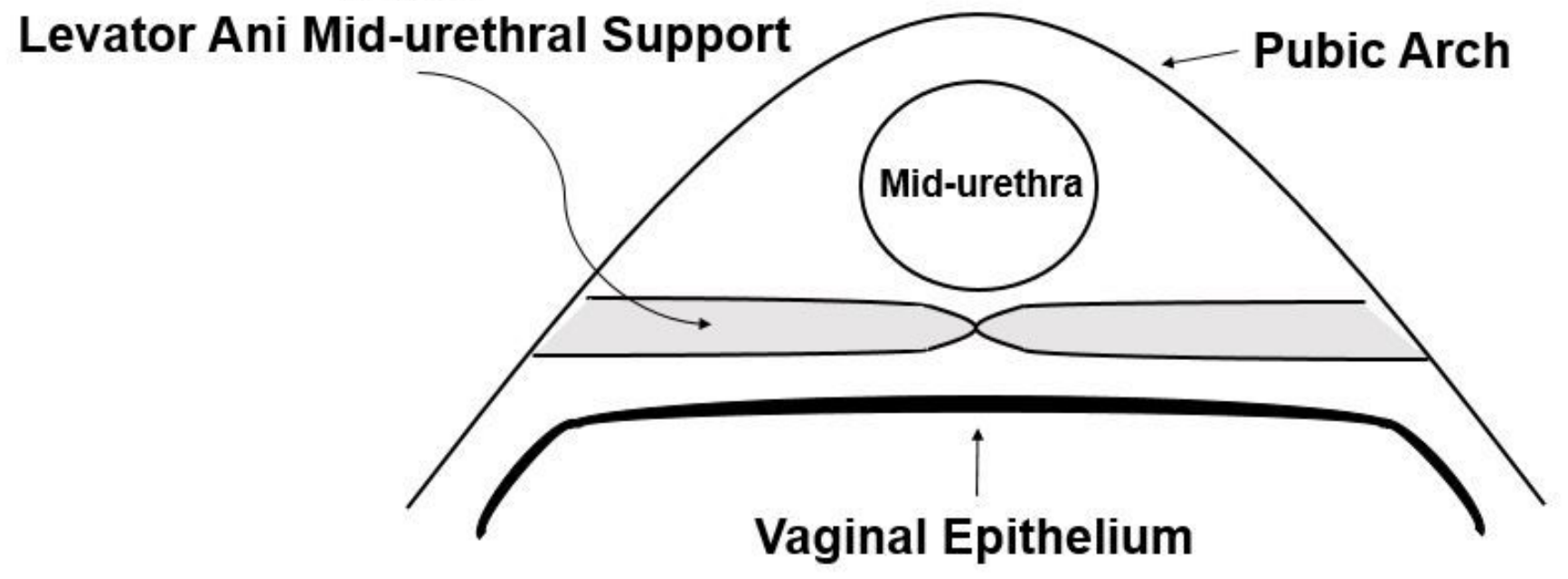

Figure 5

Schematic drawing of LAMS - midurethra axial view - after three passes of plication of levator ani muscle and the closure of the vaginal epithelium, showing support of the midurethra by a strong band of muscle; for a patient without scar tissue or suture bridge. This schematic drawing corresponds to the photograph of Figure 1 


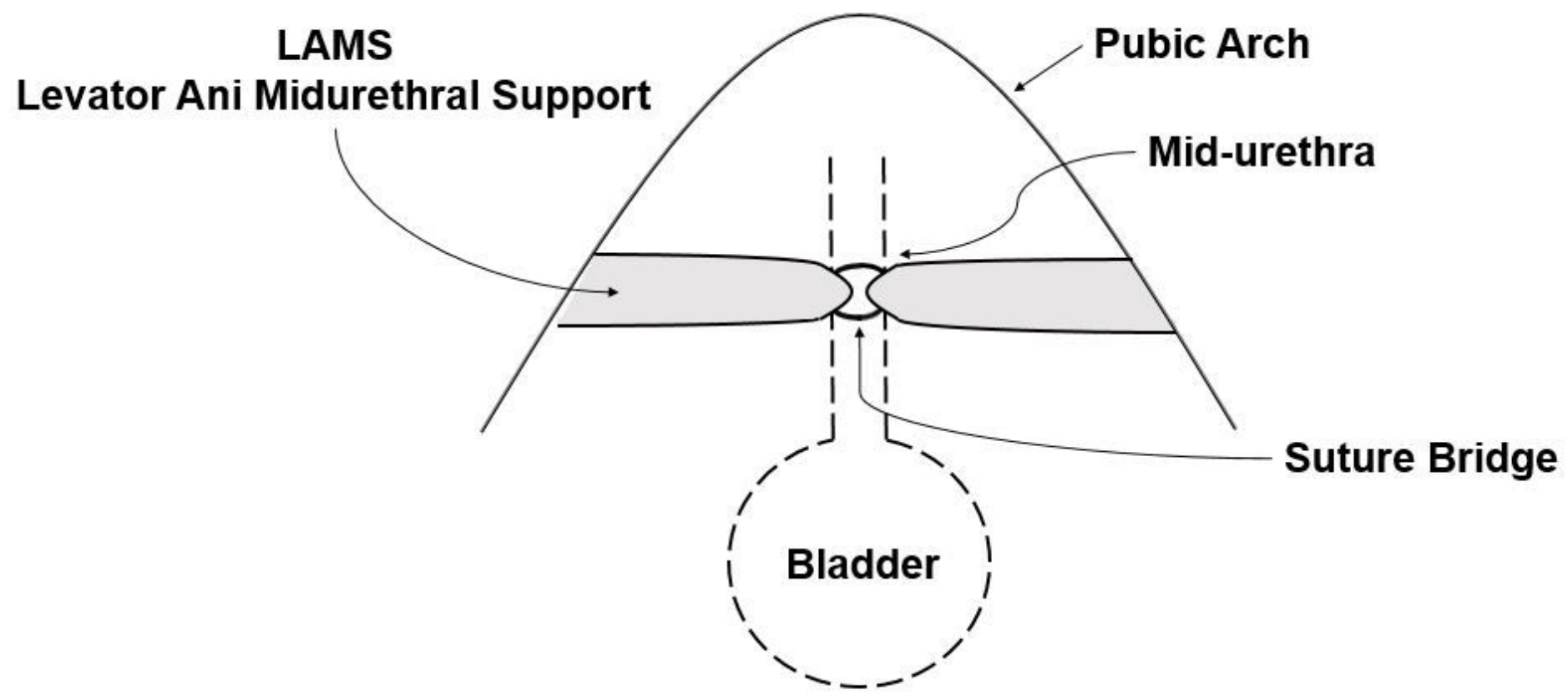

Figure 6

Schematic drawing of LAMS after three passes of plication of levator ani muscle, showing support of the midurethra by a strong band of muscle with a suture bridge; for the Case, with dense tissue scarring and suture bridge

\section{LAMS}

Levator Ani Mid-urethral Support

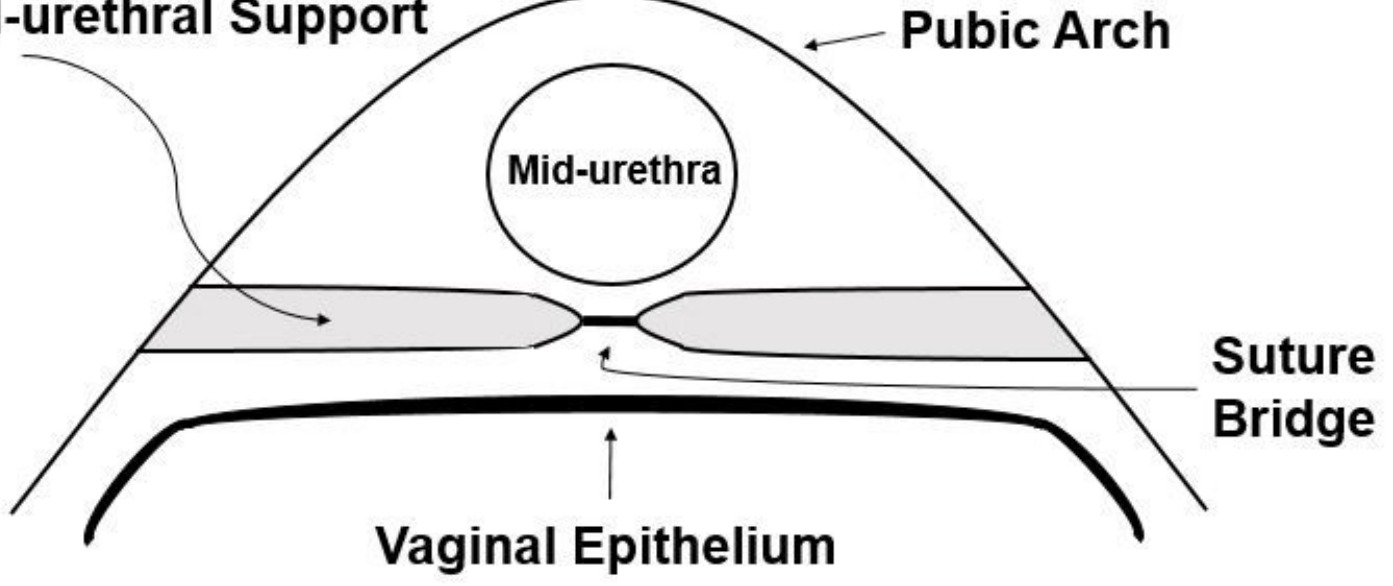

Figure 7

Schematic drawing of LAMS - midurethra axial view - after three passes of plication of levator ani muscle and the closure of the vaginal epithelium, showing support of the midurethra by a strong band of muscle with a suture bridge; for the Case, with dense tissue scarring and suture bridge 